\title{
Radiotherapy combined with gefitinib for patients with locally advanced non-small cell lung cancer who are unfit for surgery or concurrent chemoradiotherapy: a phase II clinical trial
}

Zhixue Fu, Xu Yang, Wenqing Wang, Lei Deng, Tao Zhang, Nan Bi, Xiaozhen Wang, Dongfu Chen, Zongmei Zhou, Luhua Wang and Jun Liang ${ }^{*}$ (D)

\begin{abstract}
Background: The objectives of this study were to determine the objective effective response rate, survival, and safety of radiotherapy combined with gefitinib in patients with locally advanced non-small cell lung cancer (NSCLC) who were unfit for surgery or concurrent chemoradiotherapy.

Methods: The patients with the locally advanced NSCLC who were unfit to receive surgery or concurrent chemoradiotherapy, received thoracic intensity-modulated radiotherapy (IMRT) combined with gefitinib $250 \mathrm{mg}$ daily.
\end{abstract}

Results: 29 patients were enrolled between July 2014 and March 2017. 28 patients was in the analysis. Of the 28 patients, 21 (75.0\%) experienced a partial response, 5 (17.9\%) had stable disease, and 2 (7.1\%) experienced progression of disease. The objective response rate was $75.0 \%$, and the disease control rate was $92.9 \%$. The median follow-up time was 51 months. The disease progression showed in 25 (89.3\%) patients, including local progression in 19 (67.9\%) and distant metastasis in 16 (57.1\%). The median overall survival and progression-free survival time (PFS) were 26 and 11 months, respectively. The 3-, 4-, 5-year survival rates were $39.0,30.1$ and $30.1 \%$, respectively. The 3-, 4-, 5-year PFS rates were 14.3, 9.5 and 9.5\%. Two patients developed grade 3 acute adverse events. Seven patients developed grade 2 acute irradiation pneumonitis, and there was no grade 3 acute irradiation pneumonitis.

Conclusions: For patients with locally advanced NSCLC who are not eligible for surgery or concurrent chemoradiotherapy, IMRT combined with gefitinib can improve the objective effective rate and is generally welltolerated.

Keywords: Non-small cell lung cancer, Radiotherapy, Molecular targeted therapy, Gefitinib

\footnotetext{
*Correspondence: liang23400@163.com

This study was previously oral presented as the $60^{\text {th }}$ annual meeting of

American Society for therapeutic Radiology and Oncology, San Antonio, 2124 October 2018.

Department of Radiation Oncology, National Cancer Center/National Clinical Research Center for Cancer/Cancer Hospital, Chinese Academy of Medical

Sciences and Peking Union Medical College, Beijing 10021, China
}

(C) The Author(s). 2020 Open Access This article is licensed under a Creative Commons Attribution 4.0 International License, which permits use, sharing, adaptation, distribution and reproduction in any medium or format, as long as you give appropriate credit to the original author(s) and the source, provide a link to the Creative Commons licence, and indicate if changes were made. The images or other third party material in this article are included in the article's Creative Commons licence, unless indicated otherwise in a credit line to the material. If material is not included in the article's Creative Commons licence and your intended use is not permitted by statutory regulation or exceeds the permitted use, you will need to obtain permission directly from the copyright holder. To view a copy of this licence, visit http://creativecommons.org/licenses/by/4.0/ The Creative Commons Public Domain Dedication waiver (http://creativecommons.org/publicdomain/zero/1.0/) applies to the data made available in this article, unless otherwise stated in a credit line to the data. 


\section{Background}

Lung cancer is a malignant tumor with one of the highest morbidity and mortality rates in the world, and non-small cell lung cancer (NSCLC) accounts for approximately $85 \%$ of lung cancers [1]. Approximately $30 \%$ of NSCLC are at a locally advanced stage at the time of diagnosis. Concurrent chemoradiotherapy (CRT) plus Durvalumab is the standard treatment for unresectable locally advanced NSCLC; however, not all patients with unresectable stage III NSCLC are able to tolerate concurrent CRT. Previous clinical trials have shown that among patients treated with concurrent CRT, the incidence of grade 3 and more irradiation pneumonitis and esophagitis ranged from 0 to $18 \%$ and $3.4-32 \%$, respectively [2-11]. The PACIFC study [12], durvalumb after chemoradiotherapy in stage III NSCLC, showed that a total of $30.5 \%$ of the patients in the durvalumab and $26.1 \%$ of those in the placebo group had grade 3 and more adverse events.

Among patients who are unable to tolerate concurrent CRT, the conventional treatment regimens are sequential chemotherapy and radiotherapy, or radiotherapy only, and the median overall survival (OS) is 11-16 months [2-9].

Coupled with further development of lung cancer genomics, epidermal growth factor receptor (EGFR) tyrosine kinase inhibitors (TKIs) provide an effective treatment for patients with the advanced lung adenocarcinoma. There is currently a lot of interest in targeted therapy, which has a higher efficiency and a lower toxicity.

Several trials have shown that EGFR inhibitors have a radiotherapy sensitization effect when combined with radiotherapy. The Cancer and Leukemia Group B (CALGB30106) trial [13], which evaluated the feasibility of poor-risk patients receiving radiotherapy and gefitinib (Group A) and those with a more favorable risk profile receiving concurrent CRT and gefitinib (Group B), showed that Group A had a longer MST than Group B. In RTOG 0972, a phase II clinical trial of induction chemotherapy followed by thoracic radiotherapy (TRT) and erlotinib in 75 poor-risk patients with stage III NSCLC, showed the median OS and progression-free survival time (PFS) were 17 and 11 months, respectively, and the 1-year overall survival (OS) was 75\% [14].

These trials demonstrate that radiotherapy combined with targeted therapy may be a potentially beneficial treatment for patients with locally advanced NSCLC who are unable to tolerate concurrent CRT. We conducted a phase II trial to evaluate the effectiveness of radiotherapy combined with gefitinib in patients with locally advanced NSCLC who were unfit for surgery or concurrent CRT. The primary objective of this study was to determine the objective response rate. The secondary objectives included assessing the OS, the median
OS, PFS, and the safety of radiotherapy combined with gefitinib.

\section{Patients and methods Patient selection}

The inclusion criteria were: (1) histologically or cytologically confirmed unresectable stage III NSCLC; (2) no thoracic radiotherapy history; (3) tumor objectively measured; (4) age $\geq 18$ years; (5) Karnofsky Performance Status $\geq 70$; (6) predicted survival $\geq 3$ months; (7) without severe disease of the vital organs; (8) provision of written informed consent.

The exclusion criteria were: (1) neurological disease; (2) history of recent treatment for another malignant tumor; (3) previous participation in clinical trials of other new drugs; and (4) previous targeted therapy.

The unresectable stage IIIA and IIIB NSCLC mainly refers to the following image or lymph node pathological evidence: 1. The more ipsilateral mediastinal lymph nodes merging into a great lump or multi-region metastasis (IIIA: T1-3 N2 or IIIB: T4N2); 2. The contralateral hilar,mediastinal lymph nodes; the ipsilateral /contralateral scalene, supraclavicular lymph node metastasis (IIIB: T1- N3); 3. Lesions invades into the heart, the aorta and esophagus (IIIB: T4N0-1).

The patients of NSCLC, unfitting for concurrent chemoradiotherapy, refer to the following situations: the patients refuse the concurrent chemoradiotherapy; the patients have so much basic disease that they can't toletate the concurrent CRT.

\section{Treatment}

Patients were treated with a combination of radiotherapy and gefitinib:

- Radiotherapy: Photon beams were applied with an intensity of 6-MV. The gross tumor volume (GTV) was defined as the volume of the primary disease as well as any involved regional lymph nodes (the short axis of at least $1 \mathrm{~cm}$ on computed tomography scan). The clinical target volume (CTV) included the primary tumor plus a margin of 6-8 $\mathrm{mm}$, elective nodal regions including ipsilateral hilar, paratracheal, and subcarinal nodal regions were also included in the CTV. The planning target volume (PTV) included the CTV plus a margin of $5 \mathrm{~mm}$ in 3 dimensions. The prescription dose was 95\% PTV 60-66 Gy/2 Gy/30-33 f.

- Gefitinib: An oral dose of $250 \mathrm{mg}$ was administered daily, starting on Day 1. If the treatment was effective, it was continued after radiotherapy had been completed. 


\section{Response and toxicity criteria}

The Response Evaluation Criteria in Solid Tumors (RECIST) guideline version 1.0 was used to evaluate the short-term effectiveness. The National Cancer Institute (NCI) Common Terminology Criteria for Adverse Events (CTCAE) version 3.0 was used to evaluate the toxicity.

\section{Study design}

The study was a single-arm, phase II open-label clinical trial.

\section{Calculation of sample size}

In the JCOG0301 trial [15], the objective effective rate of concurrent CRT was $51.5 \%$. We expected that the objective effective rate of TRT with gefitinib would be $68 \%$. According to the sample size calculations, at least 27 patients would be required. The target sample size was increased by $10 \%$ to 30 patient to allow for participant withdrawals.

\section{Statistical analysis}

The statistical analysis was performed using SPSS version 20.0 (IBM Corp, Armonk, NY, USA). Kaplan-Meier plots were used for survival analysis. Log-rank tests were used to assess the significance of associations in the univariate analysis. Cox regression was using to assess factors associated with survival in the multivariate analysis. Results with $p<0.05$ were considered statistically significant.

\section{Results}

\section{Patient characteristics}

From July 2014 to March 2017, 29 patients were enrolled, of which 28 were included in the analysis. One patient refused to continue radiotherapy because of the fever, so the patient was excluded from the analysis. The median age of the participants was 63 years. Of the participants, 7 (25.0\%) and 21 (75.0\%) were diagnosed with stages III A and III B NSCLC, respectively. Seventeen participants $(60.7 \%)$ had previously received platinumbased induction chemotherapy (Table 1).

\section{Treatment regimens}

Of the 28 participants, 21 received intensity-modulated radiotherapy and 7 received volumetric-modulated arc therapy. Twenty eight patients completed TRT with a dose of 54-60Gy.Twenty three patients accepted TRT with 60Gy. Three patients completed TRT with 58Gy. Because the CTV of the 3 patients is too large and the V20 of double lungs is beyond 28\%, the total dose reduced to 58Gy. Two patients accepted TRT with $54 \mathrm{~Gy}$, because they suffered from grade 2 radiation pneumonia.
Table 1 Patients' characteristics

\begin{tabular}{|c|c|}
\hline Characteristics & $N(\%)$ \\
\hline \multicolumn{2}{|l|}{ Sex } \\
\hline Male & $24(85.7)$ \\
\hline Female & $4(14.3)$ \\
\hline \multicolumn{2}{|l|}{ Age } \\
\hline Median & 63 \\
\hline Range & $42-77$ \\
\hline \multicolumn{2}{|l|}{ Smoking index } \\
\hline 0 & $7(25.0)$ \\
\hline $1-400$ & $1(3.6)$ \\
\hline$\geq 400$ & $20(71.4)$ \\
\hline \multicolumn{2}{|l|}{ KPS status } \\
\hline 70 & $2(7.1)$ \\
\hline 80 & $16(57.1)$ \\
\hline 90 & $9(32.1)$ \\
\hline 100 & $1(3.6)$ \\
\hline \multicolumn{2}{|c|}{ Weight loss within 6 months before the treatment } \\
\hline 0 & $19(67.9)$ \\
\hline$<5 \%$ & $4(14.3)$ \\
\hline$\geq 5 \%$ & $5(17.9)$ \\
\hline \multicolumn{2}{|l|}{ T stage } \\
\hline $\mathrm{T} 1$ & $1(3.6)$ \\
\hline T2 & $10(35.7)$ \\
\hline T3 & $9(32.1)$ \\
\hline T4 & $8(28.6)$ \\
\hline \multicolumn{2}{|l|}{$\mathrm{N}$ stage } \\
\hline N1 & $3(10.7)$ \\
\hline N2 & $9(32.1)$ \\
\hline N3 & $16(57.1)$ \\
\hline \multicolumn{2}{|l|}{ Clinical stage } \\
\hline$\| \mathrm{A}$ & $7(25.0)$ \\
\hline$\| \mathrm{II}$ & $21(75.0)$ \\
\hline \multicolumn{2}{|l|}{ Histological type } \\
\hline - Squamous cell carcinoma & $15(53.6)$ \\
\hline Adenocarcinoma & $12(42.9)$ \\
\hline Neuroendocrine carcinoma & $1(3.6)$ \\
\hline \multicolumn{2}{|c|}{ Inducing chemotherapy before TRT } \\
\hline Yes & $17(60.7)$ \\
\hline No & $11(39.3)$ \\
\hline
\end{tabular}

Response to treatment and toxicity

Of the 28 patients, 21 (75.0\%) experienced a partial response (PR), 5 (17.9\%) had stable disease (SD), and 2 (7.1\%) experienced progression of disease (PD). None of the patients experienced a complete response (CR). The objective response rate $(C R+P R)$ was $75.0 \%$, and the 
disease control rate $(C R+P R+S D)$ was $92.9 \%$. Twentyfive participants (89.3\%) experienced a relapse: 19 (67.9\%) experienced a local relapse, and 16 (57.1\%) experienced a distant relapse, including 10 participants (35.7\%) who experienced both a local and a distant relapse.

Overall, the toxicity results demonstrated the feasibility of this approach (Table 2). One patient (3.6\%) experienced Grade 3 liver dysfunction, esophagitis, and diarrhea, respectively. Seven participants $(25.0 \%)$ experienced grade 2 pneumonitis and there was no grade 3 acute irradiation pneumonitis.

\section{Survival}

Follow-up was censored on 15 December 2019. The 7 median follow-up time was 51 months. The median PFS was 11 months, and the MST was 26 months. The 3-, 4- and 5-year survival rates were 39.0, 30.1 and $30.1 \%$, respectively. The 3-, 4- and 5-year PFS rates were 14.3, 9.5 and $9.5 \%$, respectively. (Fig. 1).

Univariate analysis showed that only disease stage was associated with OS ( $p=0.043$, 95\%CI 11.998-40.109), and with PFS ( $p=0.000,95 \%$ CI 9.899-12.114).

The median OS of participants with stages III A and III B disease were 12 and 35 months, respectively. Participants with stage III B disease had a significantly better OS and PFS than patients with stage III A disease.

\section{Epidermal growth factor receptor mutation}

Molecular data were available for 13 participants. The EGFR-activating mutation was detected in 6 of the 13

Table 2 Acute adverse events

\begin{tabular}{lllll}
\hline Toxicity & \multicolumn{4}{l}{ Toxicity Grade } \\
\cline { 2 - 5 } & $1(\%)$ & 2 & 3 & 4 \\
& $\mathrm{~N}(\%)$ & $\mathrm{N}(\%)$ & $\mathrm{N}(\%)$ \\
\hline Skin & $9(32.1)$ & 0 & 0 & 0 \\
$\quad$ Rash & $18(64.3)$ & 0 & 0 & 0 \\
Radiation dermatitis & & & & \\
Hematologic toxicity & & 0 & 0 & 0 \\
Anemia & $9(32.1)$ & 0 & 0 & 0 \\
Leukopenia & $9(32.1)$ & 0 & 0 & 0 \\
$\quad$ Thrombocytopenia & 0 & 0 & & \\
Gastrointestinal toxicity & & & 0 & 0 \\
$\quad$ Nausea & $7(25.0)$ & $3(10.7)$ & 0 & 0 \\
$\quad$ Vomiting & $1(3.6)$ & $1(3.6)$ & 0 & 0 \\
$\quad$ Diarrhea & $1(3.6)$ & 0 & $1(3.6)$ & 0 \\
Esophagitis & $9(32.1)$ & $9(32.1)$ & $1(3.6)$ & 0 \\
Hypohepatia & $8(28.6)$ & 0 & $1(3.6)$ & \\
Renal function & $6(21.4)$ & 0 & 0 & 0 \\
Pneumonitis & $2(7.1)$ & $7(25.0)$ & 0 & 0 \\
\hline
\end{tabular}

participants (46.2\%). The 6 participants with the EGFRactivating mutation had a significantly better the median OS (39 months) than the 20 participants with the EGFR wild-type or non-adenocarcinoma (20 months) without significant difference.

\section{Discussion}

In this trial, the PR rate and the objective effective response rate were both $75.0 \%$, and the disease control rate was $92.9 \%$, and no participants experienced a CR. In previous clinical trials of concurrent CRT the CR rate was $9-28 \%$, the PR rate was $28-81 \%$, and the objective effective response rate was $43-85 \%$ [2-11, 15]. Among participants in previous studies who received radiotherapy only, or sequential chemotherapy and radiotherapy, the CR rate was $1.3-30 \%$, the PR rate was $30-65 \%$, and the objective effective response rate was $39-66 \%$. Although none of the participants in our study experienced a $C R$, the PR rate and the objective effective response rate were comparable to those of previous studies.

The reason for the absence of any participants with a $\mathrm{CR}$ in this study may be attributable to: the high proportion of participants with stage III B disease (75\%); high PTV (64.3\% had a PTV volume $>450 \mathrm{ml}$ ); the relatively small proportion of participants with adenocarcinoma (42.9\%). The relatively high PR rate and objective effective response rate compared to previous studies may be attributable to the higher rates of completion of radiotherapy (82.1\%) and targeted therapy (85.7\%).

In the CALB30106 trial [13] the high-risk group (radiotherapy and gefitinib) had a median OS of 19.0 months and median PFS of 13.4 months; while the lowrisk group (concurrent CRT and gefitinib) had a median OS of 13 months and a median PFS of 9.2 months. The survival time of high-risk patients who received sequential CRT with gefitinib is promising. Spanish researchers [16] studied 90 patients with locally advanced NSCLC. The median OS was 11.4 months among those who received radiotherapy only, and 8.9 months among those who received radiotherapy with erlotinib, and the median PFS was 15.3 months and 12.9 months, respectively. Wang et al. reported that EGFR-TKI concurrent with thoracic radiotherapy in treating stage IIIB/IV NSCLC had local control rate of $96 \%$ for thoracic tumor and 1year PFS rate of $42 \%$ [17]. Zheng et al. reported that the 1 -year PFS rate of $57.1 \%$, the median PFS 13 months and the median time to progression of irradiated lesion 20.5 months in TIK combined with radiotherapy as first line treatment for patients with stage IV NSCLC harboring EGFR active mutations [18]. In the RTOG 9410 trial [4], the median OS was 17 months among participants who received $60 \mathrm{~Gy}$ of $\mathrm{CRT}$, and 15.6 months among those who received $70 \mathrm{~Gy}$ of CRT. Compared with radiotherapy only and concurrent CRT, the survival of 


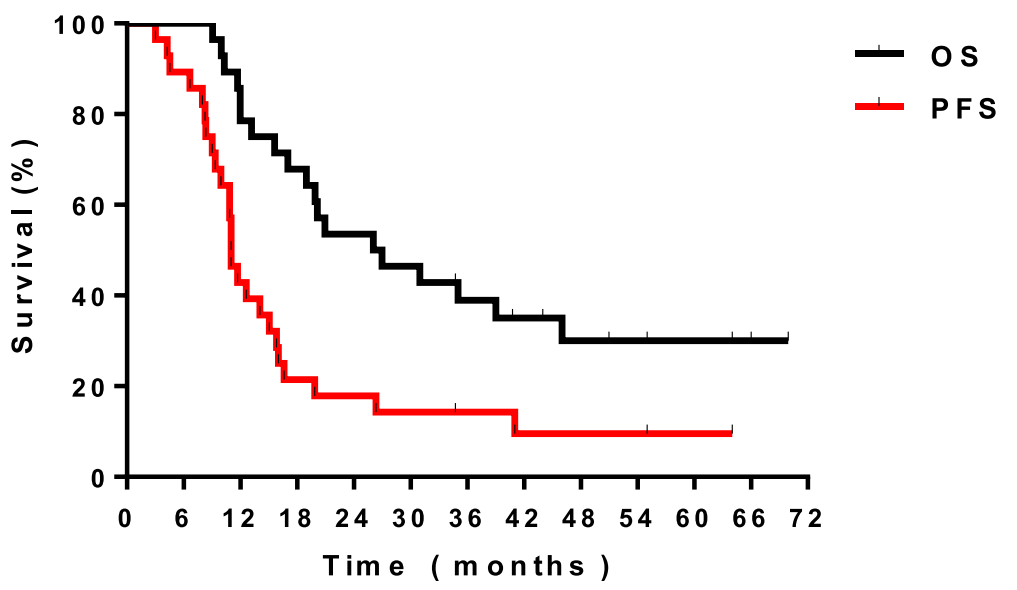

Fig. 1 The O S and P FS curves of the w hole group

participants who received radiotherapy combined with targeted therapy is comparable to that of the participants in our study.

In our study, the OS and PFS of participants with stage III B disease was higher than that of participants with stage III A disease. Possible reasons for this paradoxical result include: (1) participants with stage III A disease had more risk factors than those with III $B$ disease including older age( $\geq 65$ year; III A 5/7 (71.4\%);III B 8/21 (38.1\%);), greater weight loss (6 months before radiotherapy: weight loss $\geq 5 \%$;III A 3/7 (42.9\%);III B 2/21 (9.5\%);), more comorbidities (including high blood pressure, diabetes, heart disease and other disease; III A 6/7 (85.7\%); III B16/21 (76.2\%);), less healthy lifestyles (smoking index $\geq 400$;III A 6/7 (85.7\%);III B 14/21 (66.7\%);), and larger primary tumors (maximum diameter before radiotherapy $\geq 4 \mathrm{~cm}$;III A 5/7 (71.4\%);III B 10/21 (47.6\%);); (2) participants with stage III B disease were more likely to have adenocarcinoma and EGFR mutations than those with stage III A disease (adenocarcinoma; III A 2/7 (28.6\%);III B 10/21 (47.6\%);) (EGFR mutations; III A 1/7 (14.3\%);III B 5/21 (23.8\%);); (3) participants with stage III B disease received more induction chemotherapy (III A 3/7 (42.9\%);III B 14/21 (66.7\%);); (4) participants with stage III A disease suffered more acute toxicities (Grade 3 esophagitis; III A 1/7 (14.3\%);III B 0/21 (0);) (Grade 3 diarrhea; III A 1/7 (14.3\%);III B 0/21 (0);).

In our study, participants with the EGFR-activating mutation had a better the median OS than those with the EGFR wild-type and those with non-adeno carcinomatous tumors. This result suggests that there is an association between the EGFR mutation state and response to targeted therapy. For NSCLC, previous studies have shown that approximately $80 \%$ of patients with squamous cell carcinoma and $65 \%$ of patients with adenocarcinomas have overexpression of EGFR protein, and the overexpression state is an important factor leading to radiation resistance [19, 20]. Meta-analysis conducted in 2002 suggested that a high EGFR expression could be related to the prognosis of NSCLC [21]. However, the CALGB 30106 trial [13] did not find an association between the presence of EGFR mutations and the prognosis of NSCLC. Although the relationship between EFGR-mutation and prognosis in advanced lung adenocarcinoma was relatively clear, the heterogeneity was relatively large among participants with locally advanced lung adenocarcinoma who were able to receive radiotherapy and chemotherapy. For locally advanced lung cancer, there are no prospective studies that have assessed whether individuals with EGFR-activating mutations could benefit from targeted therapy as the firstline treatment. Our study suggests that radiotherapy combined with gefitinib could improve the survival of patients with locally advanced EGFR-activating mutation lung adenocarcinoma.

In this study, the majority of acute adverse events (92.9\%) were grades 1 and 2; only $7.1 \%$ of participants experienced a grade 3 acute adverse event, and no participants experienced a grade 4 acute adverse event. These results indicate that radiotherapy combined with gefitinib was well tolerated.

Irradiation pneumonia is an important adverse event among patients treated with TRT. In our study, the incidence of grade 2 acute irradiation pneumonitis was $25.0 \%$, but there were no cases of more than grade 3 acute irradiation pneumonitis. Compared with concurrent CRT (which has a reported rate of grade 3 acute irradiation pneumonitis of $0-18 \%$ ) [2-11], targeted therapy combined with radiotherapy did not significantly increase the incidence of related adverse events. Although irradiation pneumonia did not cause any treatment-related deaths among participants in our study, the pulmonary toxicity associated with EGFRTKIs is a cause for concern. Zheng et al. reported that 
the most common grade 3 adverse events were radiation pneumonitis (20\%) and rash (10\%) in TIK combined with radiotherapy as first line treatment for patients with stage IV NSCLC harboring EGFR active mutations [18]. A study [22] of the relationship between radiotherapy combined with erlotinib and acute irradiation pneumonitis among 24 patients with NSCLC, suggested that 9 patients (37.5\%) experienced greater than grade 2 acute irradiation pneumonitis. Other studies have shown that erlotinib can damage the lung stroma [23, 24], and erlotinib combined with TRT may increase the occurrence of acute irradiation pneumonitis. Some small sample studies $[25,26]$ also reported there was a higher incidence of acute irradiation pneumonitis among patients treated with erlotinib combined with TRT.

This trial had several limitations. First, some patients received induction chemotherapy, but the induction chemotherapy regimens and chemotherapy cycles were not standardized. Second, this study was a single-arm, phase II clinical trial with no control group. Third, the sample was small.

\section{Conclusions}

For patients with locally advanced NSCLC who couldn't receive surgery or concurrent chemoradiotherapy, TRT combined with gefitinib could improve the objective effective rate and be tolerated well.

\begin{abstract}
Abbreviations
CR: Complete response; CRT: Chemoradiotherapy;i CTCAE: Common terminology criteria for adverse events; CTV: Clinical target volume; EGFR: Epidermal growth factor receptor; IMRT: Intensity-modulated radiotherapy; MST: Median survival time; NCI: National cancer institute; NSCLC: non-small cell lung cancer; OS: Overall survival; PD: Progressive disease; PFS: Progression-free survival; PR: Partial response; PTV: Planning target volume; RECIST: Response evaluation criteria in solid tumors; SD: Stable disease; TKI: Tyrosine kinase inhibitor; TRT: Thoracic radiotherapy
\end{abstract}

\section{Acknowledgments}

We acknowledge all the investigators, patients and their families. We would like to thank Editage for English language editing.

\section{Authors' contributions}

Dr. Jun Liang had full access to all the data in the study and take responsibility for the integrity of the data and the accuracy of the data analysis. Acquisition, analysis, or interpretation of data: Xu Yang, Wenqing Wang, Lei Deng, Tao Zhang, Nan Bi, Xiaozhen Wang, Dongfu Chen, Zongmei Zhou. Drafting of the manuscript: Zhixue Fu. Supervision: Luhua Wang, Jun Liang. The author (s) read and approved the final manuscript.

\section{Funding}

This study was funded by a grant from the Chinese Geriatric Oncology Society (CGOS-02-2014-1-1-01500).

\section{Availability of data and materials}

The data and materials of this study are available from the corresponding author on reasonable request.

\section{Ethics approval and consent to participate}

This trial had approved by Ethics Committee of Cancer Institute and Hospital, Chinese Academy of Medical Sciences. Approval No. 14-091/881.
Consent for publication

Not applicable.

\section{Competing interests}

The authors have declared no conflicts of interest.

Received: 15 April 2020 Accepted: 10 June 2020

Published online: 20 June 2020

\section{References}

1. American Cancer Society. Cancer facts and figures 2007. Atlanta, GA: American Cancer Society; 2007

2. Schaake-Koning C, van den Bogaert W, Dalesio O, Festen J, Hoogenhot J, van Houtte $\mathrm{P}$, et al. Effects of concomitant cisplatin and radiotherapy on inoperable non-small-cell lung cancer. N Engl J Med. 1992;326:524-30.

3. Furuse K, Fukuoka M, Kawahara M, Nishikawa H, Takada Y, Kudoh S, et al. Phase III study of concurrent versus sequential thoracic radiotherapy in combination with mitomycin, vindesine, and cisplatin in unresectable stage III non-small-cell lung cancer. J Clin Oncol. 1999;17:2692-9.

4. Curran WJ Jr, Paulus R, Langer CJ, Komaki R, Lee JS, Hauser S, et al. Sequential vs. concurrent chemoradia- tion for stage III non-small cell lung cancer: randomized phase III trial RTOG 9410. J Natl Cancer Inst. 2011;103: 1452-60.

5. Zatloukal P, Petruzelka L, Zemanova M, Havel L, Janku F, Judas L, et al. Concurrent versus sequential chemorad- iotherapy with cisplatin and vinorelbine in locally advanced non-small cell lung cancer: a randomized study. Lung Cancer. 2004:46:87-98.

6. Huber RM, FlentjeM SM, PÖllinger B, Gosse H, Willner J, et al. Simultaneouschemoradiotherapy compared with radiotherapy alone after induction chemotherapy in inoperable stage IIIA or IIIB non small-cell lung cancer: study CTRT99/97by the bronchial carcinoma therapy group. J Clin Oncol. 2006;24:4397-404.

7. Clamon G, Herndon J, Cooper R, Chang AY, Rosenman J, Green MR. Radiosensitization with carboplatin for patients with unresectable stage III non-small-cell lung cancer: a phase III trial of the Cancer and leukemia group B and the eastern cooperative oncology group. J Clin Oncol. 1999;17:4-11.

8. Belderbos J, Uitterhoeve L, van Zandwijk N, Belderbos $H$, Rodrigus $P$, van de Vaart $P$, et al. Randomised trial of sequential versus concurrent chemoradiotherapy in patients with inoperable non-small cell lung cancer (EORTC 08972-22973). Eur J Cancer. 2007;43:114-21.

9. Groen HJ, van der Leest AH, Fokkema E, Timmer PR, Nossent GD, Smit WJ, et al. Continuously infused carboplatin used as radiosensitizer in locally unresectable non-small-cell lung cancer: A multicenter phase III study. Ann Oncol. 2004;15:427-32.

10. Fournel $P$, Robinet $G$, Thomas $P$, Souquet PJ, Léna $H$, Vergnenégre $A$, et al Randomized phase III trial of sequential chemoradiotherapy compared with concurrent chemoradiotherapy in locally advanced non-small-cell lung cancer: Groupe Lyon-saint-Etienne d'Oncologie Thoracique-Groupe Francais de PneumoCancerologie NPC 95-01 study. J Clin Oncol. 2005;23:5910-7.

11. Gervais R, Ducolone A, Lechevalier T, Legroumellec A, Lemarie E, Quoix E, et al. Conventional radiation (RT) with daily carboplatin (Cb) compared to RT alone after induction chemotherapy (ICT) [vinorelbine $(\mathrm{Vr})$-cisplatine (P)]: final results of a randomized phase III trial in stage III unresectable non small cell lung (NSCLC) cancer. Study CRG/BMS/NPC/96 of the French lung cancer study group FNCLCC and IFCT. J Clin Oncol. 2005;23:7016.

12. Ready N, Jänne P, Bogart J, DiPetrillo T, Garst J, Graziano S, et al Chemoradiotherapy (CRT) and geftinib $(G)$ in stage III non-small cell lung cancer (NSCLC): a CALGB stratifed phase II trial. J Clin Oncol. 2006;24(Suppl 1):7046.

13. Antonia SJ, Villegas A, Daniel D, Vicente D, Murakami S, Hui R, et al. Overall survival with Durvalumab after Chemoradiotherapy in stage III NSCLC. N Engl J Med. 2018;379(24):2342-50.

14. Lilenbaum R, Samuels M, Wang X, Kong FM, Jamme PA, Masters G, et al. A phase II study of induction chemotherapy followed by thoracic radiotherapy and erlotinib in poor-risk stage III non-small-cell lung cancer: results of CALGB 30605 (Alliance)/RTOG 0972 (NRG)[J]. J Thorac Oncol. 2015; 10:143-7.

15. Atagi S, Kawahara M, Yokoyama A, Okamoto H, Yamamoto N, Ohe Y, et al. Thoracic radiotherapy with or without daily low-dose carboplatin in elderly patients with non-small cell lung cancer: a randomized controlled, phase 3 
trial by the Japan clinical oncology group (JCOG 0301). Lancet Oncol. 2012;13:671-8.

16. Martínez E, Martínez M, Rico M, Hemández B, Casas F, Viñolas N, et al. Feasibility, tolerability, and effcacy of the concurrent addition of erlotinib to thoracic radiotherapy in locally advanced unresectable non-small cell lung cancer: a phase II trial. Oncol Targets Ther. 2016;9:1057-66.

17. Wang J, Xia TY, Wang YJ, Li HQ, Li P, Wang JD, et al. Prospective study of epidermal growth factor receptor tyrosine kinase inhibitors concurrent with individualized radiotherapy for patients with locally advanced or metastatic non-small cell lung cancer. Int J Radiat Oncol. 2011;81:e59-65.

18. Zheng LP, Wang Y, Xu Z, Yang Q, Zhu G, Liao XY, et al. Concurrent EGFR-TK and thoracic radiotherapy as first line treatment for stage IV non-smallcell lung cancer harboring EGFR active mutations. Oncologist. 2019;24: 1031-e612.

19. Ciardiello F, Tortora G. EGFR antagonists in cancer treatment. N Engl J Med. 2008:358:1160-74.

20. Dacic S, Flanagan M, Cieply K, Ramalingam S, Luketich J, Belani C, et al. Significance of EGFR protein expression and gene amplification in nonsmall cell lung carcinoma. Am J Clin Pathol. 2006;125:860-5.

21. Meert AP, Martin B, Delmotte P, Berghmans T, Lafitte JJ, Mascaux C, et al. The role of EGFR expression on patient survival in lung cancer: a review with meta-analysis. Eur Respir J. 2002;9:75-81.

22. Zhuang H, Yuan Z. Radiation pneumonitis in patients with non-small cell lung cancer treated with erlotinib concurrent with thoracic radiotherapy. J Thorac Oncol. 2014;9:882-5.

23. Ren S, Li Y, Li W, Zhao Z, Jin C, Zhang D. Fatal asymmetric interstitial lung disease after erlotinib for lung cancer. Respiration. 2012;84:431-5.

24. Tsubata Y, Hamada A, Sutani A, Isobe T. Erlotinib-induced acute interstitial lung disease associated with extreme elevation of the plasma concentration in an elderly non-small-cell lung cancer patient. J Cancer Res Ther. 2012;8: 154-6.

25. Nanda A, Dias-Santagata DC, Stubbs H, O'Hara CJ, Zaner KS, Lynch TJ, et al. Unusual tumor response and toxicity from radiation and concurrent erlotinib for non-small-cell lung cancer. Clin Lung Cancer. 2008;9:285-7.

26. Chang CC, Chi KH, Kao SJ, Hsu PS, Tsang YW, Chang HJ, et al. Upfront geftinib/erlotinib treatment followed by concomitant radiotherapy for advanced lung cancer: a mono-institutional experience. Lung Cancer. 2011; 73:189-94.

\section{Publisher's Note}

Springer Nature remains neutral with regard to jurisdictional claims in published maps and institutional affiliations.

Ready to submit your research? Choose BMC and benefit from:

- fast, convenient online submission

- thorough peer review by experienced researchers in your field

- rapid publication on acceptance

- support for research data, including large and complex data types

- gold Open Access which fosters wider collaboration and increased citations

- maximum visibility for your research: over $100 \mathrm{M}$ website views per year

At $\mathrm{BMC}$, research is always in progress.

Learn more biomedcentral.com/submissions 